\title{
CENSUS SURVIVAL RATIO ESTIMATES OF NET MIGRATION FOR CANADIAN REGIONS*
}

\author{
R. Marvin Mclnnis \\ Queen's University, Kingston, Ontario, Canada
}

Résumé-On a relevé dans plusieurs études que la méthode 'Census Survival Ratio' (CSR) fournit les estimations les plus sûres de la migration interne d'un pays. La méthode CSR, se servant des données sur Canadiens et Canadiens nés aux États Unis. Plusieurs problèmes concernant l'usage des données sur Canadiens nés aux États Unis y sont énumérés. Les estimations sont comparées à celles obtenues par d'autres auteurs utilisant d'autres méthodes. On démontre dans cette étude que les erreurs d'énumération d'un genre bien connu, afflige les totaux de recensement Canadian tellement que les ignorer mène à des fausses estimations de la migration.

Abstract-It has been noted in several studies that the Census Survival Ratio (CSR) method produces the most reliable estimates of internal migration in a country. The CSR method, making use of both Canadian and the Canadian-born in the U.S. data, is employed to develop estimates of net migration between the different regions in Canada. Several problems in using the Canadian-born in the U.S. data are enumerated. The estimates are compared with estimates obtained by other authors utilizing other methods. The paper demonstrates that enumeration errors of a well-known sort afflict Canadian census totals to such an extent that ignoring them leads to faulty estimates of net migration.

\section{Why Census Survival Ratio Estimates?}

Internal migration in Canada has only recently begun to be studied with any degree of thoroughness. At that, most of the studies that have been carried out have focussed on a very recent period. Until a question on five-year migration was asked on the census of 1961, good data on internal migration in Canada was scarce. Several sets of historical estimates of provincial net gains and losses due to migration have been made, by various techniques. Some of these have been widely used (D.B.S., 1963; Anderson, 1966) but questions about their reliability have rarely been asked.

The present paper is almost wholly concerned with the accuracy and reliability of net migration estimates. There may be no final resolution of a single best set of provincial net migration estimates, however, sources of errors and their approximate magnitudes should be more widely appreciated than they are. A similar paucity of historical migration estimates was encountered in the U.S. Out of the substantial body of research that sprang up to deal with the problem, a lot was learned about the nature of errors in migration estimates. One of the more interesting developments in that literature has been the realization that the Census Survival Ratio (CSR) method, developed to produce historical estimates of net migration for periods before national vital registration, had the added virtue of greater reliability than Vital Statistics or Life Table Survival Ratio (LTR) Methods estimates (see Hamilton, 1966; Zachariah, 1962).

Canada also lacks historical vital registration and life tables. It is worth investigating whether the CSR method could be used to produce better net migration estimates for Canadian provinces and regions too.

There are basically four alternative sets of estimates of provincial net migration

*An invited paper. 
available for Canada. What might be regarded as the classic estimates are those of Keyfitz (1950) computed by the Life Table Survival Ratio (LTR) method, covering the whole of the period from 1851 to 1941 . For the period prior to 1931 these estimates were produced by projecting backward the Canadian life table of 1931 on the trend of that for England and Wales. That is a wholly conjectural historical projection so the estimates for decades prior to the census of 1931 have to be regarded on a distinctly different basis from those since. Keyfitz gave no age or sex detail for provincial estimates but his method would readily permit its calculation and Stone has indeed undertaken that in his 1961 Census Monograph (Stone, 1969). A distinctly different set of estimates, again with no age detail and also for all decades since 1871 was presented by Buckley (1962) using data on province of birth and province of residence. Buckley compared his results with Keyfitz's and found them to be broadly similar. However, as one might expect from the different methods of estimation, some substantial differences do occur, differences that are at least sufficient to call for further questioning. A third type of estimates are those based on the Vital Statistics method. Such estimates have been produced by the Dominion Bureau of Statistics for intercensal decades and adapted by Isabel Anderson to calendar year intervals (D.B.S., 1963; Anderson, 1966). Again the age structure of migration is not given.

Finally, mention should be made of the "Place of Birth Survival Ratio" (PBSR) estimates by M. V. George (1970) which have appeared since the estimates reported in this paper were originally produced. These are a sort of modification of CSR estimates, which George also made but relegated to the background in favour of his PBSR estimates. Discussion of these is left to a later juncture where I compare my. CSR estimates with George's alternative.

The available estimates of regional migration in Canada reflect almost the full variety of methods of estimation that have been developed elsewhere and discussed in the literature. The Census Survival Ratio method that has increasingly received attention in writings in the U.S. on migration estimates has tended to be ignored in Canada, though. Elsewhere, the CSR method has been found attractive, in part because it is economical of data (it requires only readily available census statistics) but more because it provides some degree of correction of errors of enumeration of the census data. These errors of enumeration are significant, and probably the major source of error in any residual type of migration estimate, whether it uses vital statistics or survival ratios. This is especially the case with estimates for individual age classes for which enumeration errors are produced not only by the failure of the census to count people at all but also by its failure to record them in the correct age class. In effect, CSRs, as measures of survivorship, are in error by design in order to offset the enumeration errors in the census population numbers to which the CSRs are applied in the process of making estimates of migration.

The important characteristics and the relative merits of CSR estimates of migration have been ably discussed elsewhere (see especially Lee, et al., 1957; Price, 1955; Tarver, 1962; Zachariah, 1962; and Hamilton, 1966). In the following paragraphs I merely summarize the main points in order to support my contention that of the various approaches to estimating net migration as a residual, the CSR method may produce the most reliable results. If we are really concerned with developing as reliable estimates of migration as we can for the provinces and regions of Canada, we ought to explore the CSR method to ascertain whether the basic conditions for its application can be met in the Canadian case.

As has already been alluded to, the chief advantage of CSR estimates is that, if expressed as rates of migration with an appropriately selected base population, they tend to cancel out census enumeration errors and thereby produce more reliable estimates of net migration. Admittedly, the estimates may still be subject to the well-known "structural 
error." On the other hand, Life Table Survival Ratio or Vital Statistics methods, which more accurately account for deaths tend to misstate net migration by the amount of net census error. Consider a group that frequently tends to be seriously underenumerated such as males aged 25-29. Applying a correct measure of survival produces an underestimate of 3539 year-olds ten years later and hence an upwardly biased estimate of migration. The reverse would be true for an age class where the relative degree of enumeration is lower in the second census, such as the age group 15-19. A census survival ratio estimate that met all other necessary conditions would offset this error. This can be demonstrated by restating the forward survival ratio estimating equation (1)

$$
M=P_{1}-R P_{0}
$$

in a form that incorporates erroneously enumerated populations $\left(\mathrm{P}^{*}\right)$ rather than true populations (P). Equation (2)

$$
M=P *_{1}-P_{0}^{*} \frac{\bar{P}_{1}^{*_{1}}}{\overline{P^{*}}}
$$

substitutes $P^{*}$ for $P_{1}, P^{*}$ for $P_{0}$ and $\frac{\bar{P}^{*}{ }_{1}}{\bar{P}_{0}^{*}}$, the national native-born census survival ratio for $\mathrm{R}$. We can define $P^{*}$-the actually enumerated population-as the product of the true population and $\mathrm{E}$, the degree of enumeration error.

$$
P^{*} \equiv E P
$$

Writing $E_{0}$ and $E_{1}$ for the degrees of enumeration error in the earlier and later census populations and $e_{0}$ and $e_{1}$ for the comparable errors in the measured national native-born populations that form the CSR, we can express the equation for the estimate of migration in terms of erroneously enumerated populations.

$$
M=E_{1} P_{1}-E_{0} P_{0} \frac{e_{1} \bar{P}_{1}}{e_{0} \bar{P}_{0}}
$$

Further, we can write $e_{0}=\lambda E_{0}$ and $e_{1}=\lambda E_{1}$ by an appropriate selection of the constants $\lambda_{0}$ and $\lambda_{1}$. Then

$$
M=E_{1} P_{1}-E_{0} P_{0} \frac{\lambda_{1} E_{1} \bar{P}_{1}}{\underline{\lambda_{0} E_{0} \bar{P}_{0}}},
$$

for which $E_{0}$, the errors of enumeration in the base population cancel, leaving only the enumeration error in the terminal population. If the forward CSR estimate is converted to a ratio, $m$, through division by $E_{\mathrm{l}} P_{1}$ (the measured terminal population) the $E_{1}$ error terms also cancel and the migration ratio is

$$
m=\frac{P_{1}-P_{0} \frac{\frac{\lambda_{1} \bar{P}_{1}}{\lambda_{0} \bar{P}_{0}}}{P_{1}}}{}
$$

Equation (6) produces the desired estimate of migration (again ignoring the "structure error") if

$$
\lambda_{1}=\frac{e_{1}}{E_{1}} \text { and } \lambda_{0}=\frac{e_{0}}{E_{0}} \text { or } \frac{e_{1}}{e_{0}}=\frac{E_{1}}{E_{0}} .
$$

This is the condition demonstrated by Zachariah (1962) and requires that the degree of error in the terminal population, relative to that in the base population be proportional to the degree of error in the national population used to calculate the CSR. Assuming Zachariah's condition were met-that regional survivorship did not differ from national survivorship and that the CSR is calculated from a truly closed population-the CSR method would produce a reliable estimate of migration. Although these conditions may be difficult to meet, they may be less stringent than those required to produce accuracy with LTR or VS estimates.

From research that has been done in the U.S., there seems to be a sufficient presump- 
tion that under a wide range of conditions, the CSR method may produce the most reliable estimates of migration (Hamilton, 1966), that the construction of Canadian estimates by this method warrants exploration. At the same time, an examination of the problems that arise in making Canadian estimates may offer some insight into the sensitivity of migration estimates to variations in the degree to which assumptions underlying the methods of estimation fail to hold, and to manipulations of the data used in making the estimates. We ask, how fragile is the CSR method? The discussion proceeds by reviewing first the requirements of the CSR method and then the data available for producing CSRs for Canada. Some critical aspects of these data are described and then a set of CSR estimates presented. Finally, the CSR estimates are compared with estimates made by other methods in order to evaluate the difference in results.

\section{Requirements of the CSR Method}

The assumptions and requirements of the CSR method of estimating migration have been ably discussed elsewhere and are now well known to those working in the area of migration analysis (see especially Hamilton, 1966). I need only to review them briefly here. The chief characteristic of a CSR estimate is that it is calculated entirely from census data. In the case of the forward survival ratio, considered here exclusively, the ratio of a particular age cohort in a decennial census population to the same cohort in the census ten years earlier is taken to express the combined effect of survivorship and census enumeration error. Under three conditions this CSR will produce an estimate of net migration that differs from "true" migration only by the amount of the structural bias that may result from the application of the survival ratio to the population residing in the region at the beginning of the period (a bias that depends for its magnitude upon the timing of in- and out-migration over the course of the decade). These conditions are that:

(1) the population cohort used to form the survival ratio is closed in that there is no migration and that the cohort is diminished only by death,

(2) true survivorship, reflecting the force of mortality, is the same for the region for which migration is estimated as for the population used in forming the CSR,

(3) the error of enumeration in the terminal census bears the same proportion to the error in the initial census in the regional as in the national population, or in terms of equation (6) above, $\frac{\lambda_{1}}{\lambda_{0}}=1$.

Where data are available that meet these conditions, or at least approximate them closely enough, the calculation of CSRs is a relatively straightforward matter. The widest application of the technique has been in the U.S. where closed cohorts are approximated by the native-born population and state or regional variations in mortality can be incorporated through adjustment factors or simply neglected because they are not significant. Somewhat rougher approximations have been made for India (Zachariah, 1964).

\section{Data Available for Canadian Census Survival Ratios}

The chief stumbling block in the way of constructing CSRs for Canada is the difficulty of obtaining closed population cohorts. Native-born Canadians have emigrated, and often in large numbers. However, since their migration has been almost entirely to the U.S., it should in principle be possible to achieve closure by pooling the Canadian-born of each age residing in the U.S. with those residing in Canada. While there are practical problems in doing this that cannot be lightly glossed over, such a pooling approach appears to be feasible and provides a basis for the estimates produced in this paper. There remains a serious question about the interpretation of these "mongrel" CSRs in relation to the underlying assumptions reviewed in the preceding section. The main value of using the pooled native- 
born cohort approach must lie in the results. Thus the really critical issue, to be addressed in a later section of the paper, is whether the CSR estimates produced by pooling censuses of two countries differ from Life Table Survival Ratio estimates in the way that one would expect them to, on the basis of what general knowledge there is about census enumeration errors; whatever the outcome, though, we learn some interesting things about census enumeration error. For the remainder of this section, the discussion concentrates on the conceptual and practical problems of which the pooling technique gives rise.

Even if we had available from both the Canadian and the U.S. censuses statistics of Canadian-born persons by age and sex in the form and of a quality that we desire, we would still face a serious difficulty. The CSR that we produced would have the desirable properties of CSRs only if we could assume that the pattern of errors of enumeration was the same in the Canadian and U.S. censuses. After all, the rationale of the CSR in the first place is to incorporate into the survival ratio a correction factor for the errors of enumeration in the census populations that get used in conjunction with that survival ratio. The net balancing of error that is achieved is obtained by introducing into the survival ratio precisely the error of enumeration in the population being survived. In the case at hand, Canadian regional populations are survived to produce estimates of regional net migration but the CSR includes errors of enumeration in both the Canadian and the U.S. censuses.

The welding together of error components from two separate censuses does not really introduce a new category of problem. It can be thought of as a complication of the condition that the ratios of terminal to initial census enumeration errors be the same for the population for which migration is being estimated as for the population cohort used to compute the CSR. It is still the case that $E_{1} / E_{0}=e_{1} / e_{0}$ but the $e$ terms must now be thought of as weighted averages of degrees of enumeration in the Canadian and U.S. censuses where the weights are the proportions of the Canadian-born recorded in each census. It is important to emphasize that the weights, the distribution of each cohort of Canadian-born between Canada and the U.S., enter into the picture as well as the degree of enumeration. It would be false optimism to place any emphasis on the conceptual possibility that $E_{1} / E_{0}=e_{1} / e_{0}$ could get more nearly satisfied under these new conditions than where only one census administration is involved. The main point is that if it uncertain that the condition is likely to be satisfied under the usual circumstances where only one census is involved, it is likely to be even more difficult to satisfy the condition under more complicated circumstances. To some degree each national census will have its own peculiarities and a resulting degree of accuracy. More importantly, changes from census to census in the degree of accuracy, the factor that is really critical to the condition that $E_{1} / E_{0}=e_{1} / e_{0}$, come about because of changes in census-taking practice and changes in the conditions under which censuses are taken. These are likely to be sufficiently peculiar to individual nations that, in the general case, we are quite unlikely to be able to pool censuses to produce CSRs and have any assurance that the condition for reliable application of those CSRs has been met.

I would argue, though, that the Canadian case is not the general one, but unique. Most of the conditions that affect the degree of census enumeration are common to Canada and the U.S. The societies are remarkably similar in most respects. Census-taking practice in Canada has long adhered closely to the practice and procedures of the U.S. There is a strong likelihood, then, that patterns of census enumeration error will not be very different between the two countries. Indeed one might not expect the difference between Canada and the U.S. in this respect to be notably greater than the variations among the individual states of the U.S. The requirement $E_{1} / E_{0}$ be equal to $e_{1} / e_{0}$ may therefore be a little more stringent in the case of pooled Canadian-U.S. CSRs than in the case of estimates to be applied to individual states in the U.S. This is especially so when we recall that the census 


\section{R. Marvin McInnis}

errors in the U.S. that are relevant are those applying to the enumeration of Canadian-born residing in that country. These people live in areas that are most similar to Canada and they probably carry with them cultural influences that would make their responses to census questions more similar to those of Canadian-born residing in Canada. The point is only asserted; yet it must be emphasized that it is central to the contribution of this paper. The outcome would surely be more satisfactory if there were concrete evidence supporting this assertion but we know far too little about census errors. Generally the assertion is based on vague and inferential evidence. However, I believe it to be adequate to warrant further pursuit of CSR estimates of migration for Canada utilizing the pooled Canadian-born population of the two countries.

In addition to the issue of the admissibility in principle of the pooling technique there are some practical problems relating to the census data for the two countries. : One is that the censuses are taken at different times. Another is that information about the Canadianborn collected and tabulated in U.S. censuses is limited; indeed, for the purpose at hand it might almost be described as minimal.

Consider the second of these problems first. Statistics of the Canadian-born population of the U.S., tabulated by sex and detailed age classes, are available in a form and a quality adequate for our purpose only for the decades beginning with the census of 1930 . At least as it is presented in this paper, then, the CSR technique does not produce the long historical series of migration estimates keenly needed for Canada.

For no year is there in the U.S. a full-count, complete tabulation of the Canadian-born by sex and five-year age classes comparable to what we have in the censuses of Canada. The U.S. data are in all cases samples, of varying form, and in some cases grouped into ten-year rather than five-year age classes. I have manipulated these data to establish fiveyear age distributions of the whole Canadian-born population of the U.S. for the census years 1930 through 1960 . The quality of migration estimates that can be produced must inevitably be reduced by these variations in the published data. However, the critical question that is raised throughout this paper is how far one can go with rather weak data and still produce viable CSRs. The answer has to be sought in the results.

The data from the U.S. census of 1950 (Special Report P-E, No. 3A) are the most nearly complete. They were derived from a 20 per cent sample of the entire country and show persons of Canadian nativity by five-year age groups. These data have not been altered in any way and I shall not comment on them other than to point out that they should be little more problematic than the data for 1950 on U.S: natives by age and sex that have been used in several calculations of CSRs for the U.S.

The statistics for 1960 [Final Report PC(2)-1A] differ only in that they are classified by ten-year age groups. Rather than make do with CSRs for ten-year rather than five-year age groups, I have split the ten-year classes of 1960 into five-year classes on the basis of the expected survivors of the five-year classes of 1950 . This calculation is not central to the issue that is of primary concern to this paper-whether the pooled CSR technique is viable. If the main point is tenable and the procedure for splitting the ten-year age groups is questionable, the estimates could always be regrouped into ten-year age classes.

The data for 1930 and 1940 are more problematic although the source of the difficulty is not the same in the two years. The least satisfactory data are those for 1940 (U.S. Census Bureau, 1943). The U.S. census of that year provided an age breakdown of the Canadianborn only for a 5 per cent sample of the Canadian-born of Canadian parentage. About one-quarter of the Canadian-born residing in the U.S. in 1940 were of other than Canadian parentage. The few possible tests suggest that no sizable error is introduced by assuming the same age distribution for the Canadian-born of other than Canadian parentage as for 
those with Canadian parentage. For most periods the former group would probably tend to be younger than the latter, but migration from Canada to the U.S. had dropped to a low level during the decade $1930-40$ and that would tend to minimize the proportion of younger and newer migrants among the Canadian-born in the U.S., a larger proportion of whom would have non-Canadian parentage. The age differences that one might have expected under more normal circumstances would be minimized for the 1940 population. Because of the low level of migration during the 1930 s, the 1940 Canadian-born in the U.S. would consist almost entirely of the survivors of those in 1930. This characteristic can be used to evaluate the age composition of the Canadian-born in 1940.

The age distribution in 1940 of the Canadian-born of Canadian parentage turns out to be very close to what one would expect for all Canadian-born on the basis of the survivors of the Canadian-born enumerated in 1930. While this check comes out surprisingly closely, it has to be recognized that it is contingent upon the reliability of the 1930 age distribution-a matter that has yet to be discussed. A comparable check, working backwards from 1950, is more problematic. There was such a large number of Canadianborn migrants to the U.S. between 1940 and 1950 and they were so markedly younger than the survivors of the 1940 residents that "reviving" the 1950 population produces a strikingly younger age distribution than the one observed in 1940. Migration is so heavily concentrated in the younger ages, though, that above 35 (i.e. age 45 in 1950) the "revived" 1950 Canadian-born have an age progression that corresponds closely to that for the Canadianborn of Canadian parentage in 1940.

No really firm check can be made of the validity of applying the age distribution of the Canadian-born of Canadian parentage of all Canadian-born in the U.S. About all that can be said of the procedure is that it appears to be workable for the particular period under consideration. The weakness of the 1941 Canadian-born data will have to be kept in mind when considering Census Survival Ratios and migration estimates for periods utilizing those data.

A major difference between the work of M. V. George (1970) and the estimates of this present paper concerns the handling of the Canadian-born residing in the U.S. in 1940. George puts aside the U.S. census data of that year and simply assumes that the Canadianborn in the U.S. had the same age composition as the foreign-born in Canada. He does not seem to appreciate that the Canadian-born population of Canadian parentage in the U.S. in 1940 is available, distributed by age, as well as the total white population of Canadian parentage (U.S., Bureau of the Census, 1943). The Canadian-born of Canadian parentage amounted to roughly two-thirds of the total Canadian-born in the U.S. The essential question is whether this age distribution would have differed significantly. That, in turn, would have been a matter of the timing of the preceding migration from Canada to the U.S. Canadian-born of non-Canadian parentage (including many of U.S. parentage) would have come from different parts of Canada. In principle, one would have expected them to be more recent migrants and younger on average. However, the special circumstances of the ten-year period preceding the U.S. census of 1940 modified that. Migration generally from Canada to the U.S. was at a low ebb during the Great Depression, whereas just before that, in the 1920s, the heaviest migration from Canada to the U.S. had been from the Maritime provinces and had been most heavily of Canadian-born of Canadian parentage. These special circumstances helped to make the age distribution of the Canadian-born of Canadian parentage an adequate basis for allocating all Canadian-born in the U.S. by age.

The statistics for 1930 are not quite so problematic but they are somewhat less firm than the reasonably straightforward tabulation available for 1950 . Canadian-born in the U.S. by sex and five-year age classes for 1930 is provided by Truesdell (1943, pp. 128-129). 


\section{R. Marvin McInnis}

Truesdell obtained the classification by five-year age classes by distributing all Canadianborn in the U.S. within twenty-year age classes on the basis of the five-year classes of a sample for twelve states (see Truesdell, p. 120). The twelve-state sample was not designed to be representative of the Canadian-born population. The most serious difficulty with the twelve-state sample is that it is rather overrepresentative of older areas of Canadian migration to the U.S. states which were important destinations of the Canadian immigrants of the 1920s. Michigan and California, in particular, are excluded. Comparison of the broader age classes for which the distributions of all Canadian-born in the U.S. is known bears out the upward bias in age in the twelve-state sample. To some degree, this will probably carry over into the five-year age classes, especially within the important group 25-44 years of age. There is most likely an upward bias to the 35-39 and 40-44 year classes and a downward bias to the 25-29 and 30-34 year groups. We should at least be wary of the resulting migration estimates for those groups.

A second type of difficulty arising from the use of statistics on the Canadian-born in the U.S. in conjunction with those in Canada stems from the difference in timing of the censuses of the two countries. Censuses of Canada were taken in June 1931, 1941, etc., whereas the Canadian-born in the U.S. were enumerated as of April 1930, 1940, etc. This gives rise to two problems. What is likely the lesser of the two is that the age cohorts of pooled Canadian-born that are formed mix persons in the U.S. who were in the same age class fourteen months earlier. So long as both segments of the cohort are being compared over a constant ten-year interval, this should not materially affect the outcome. The more serious problem is that individuals could be counted twice by moving from the U.S. to Canada in the interval between the two censuses; or they could be missed entirely if they migrated from Canada to the U.S. between the dates of the U.S. and the Canadian censuses. These errors are offsetting, yet even if the flow of migration in the two directions were equal in size, the Canadian-born returning from the U.S. would likely tend to be older than Canadians migrating to the U.S.

What data are available are too scanty to permit a careful investigation of this problem. The statistical record of returning Canadians (Urquhart and Buckley, 1965, Series A-339) is especially dubious. In most years it is probably a serious understatement of the actual movement. It suggests, however, that for most of the period under study the number of Canadian-born returning from the U.S. was substantially less than the number of Canadian-born emigrants to the U.S. In both directions the flows in the relevant years are rather small and the degree of offset about the same so that the effect on Census Survival Ratios should be minimal. In 1930-31, on the other hand, the Canadian-born returning to Canada substantially outnumbered those migrating to the U.S. The 1930-31 age cohorts, especially for ages 30 to 50, may be overstated and the 1931-41 CSRs thereby understated. Even so, the magnitude of this bias will still be small. A rough check suggests that the maximum bias for an estimate of migration for the age groups that are likely to be most affected is in the order of two per thousand.

The decade $1931-41$ is the earliest for which Canadian CSRs can reliably be computed by the technique of pooling Canadian-born in the U.S. with those in Canada. Statistics of Canadian-born by sex and age in the U.S. are not available for census years prior to 1910 . The data for 1910 are good but those for 1920 are too sketchy to be usable. For 1920 age detail is available only for a sample of four states and four large cities. The age composition of Canadian-born in the sample is fairly representative but not at the level of accuracy required for the construction of Census Survival Ratios.

In general, it is evident that the data available for the construction of Census Survival Ratios for Canada are to some degree problematic. The difficulties that they entail are such 
that the application of the technique is not as straightforward as it is for the U.S. The issue raised by this paper, however, is whether the method is viable in the Canadian case. To get any closer to an answer to that requires an examination of the results.

\section{Census Survival Ratios for Canada}

Census Survival Ratios for Canada for the three intercensal decades 1931-41, 1941-51 and 1951-61, calculated from the pooled Canadian-born population as described in the foregoing section, are presented in Table 1. An examination of these CSRs in the light of what we might expect them to show indicates that they are at least plausible. Although for reasons that will be elucidated below these figures must be used with considerable caution, they may have some significant implications for the evaluation of Canadian census enumeration. The CSRs show fairly clear evidence of a failure to achieve complete closure of the population at older ages so that we might expect their usefulness for making migra-

TABLE 1. FORWARD CENSUS SURVIVAL RATIOS

(Based on Pooled Canadian-Born Population)

\begin{tabular}{|c|c|c|c|}
\hline $\begin{array}{l}\text { Age at end of } \\
\text { decade }\end{array}$ & $7931-1941$ & $1941-1951$ & $1951-1961$ \\
\hline & Males & & \\
\hline $\begin{array}{c}10-14 \\
15-19 \\
20-24 \\
25-29 \\
30-34 \\
35-39 \\
40-44 \\
45-49 \\
50-54 \\
55-59 \\
60-64 \\
65-69 \\
70-74 \\
75+\end{array}$ & $\begin{array}{r}1.01134 \\
.97303 \\
.94423 \\
.92684 \\
.93533 \\
.99995 \\
.99394 \\
.94814 \\
.92773 \\
.87922 \\
.81640 \\
.78990 \\
.69856 \\
.37619\end{array}$ & $\begin{array}{r}1.02724 \\
.96249 \\
.92258 \\
.92289 \\
.94863 \\
.99287 \\
.98541 \\
.92828 \\
.91650 \\
.84499 \\
.80436 \\
.78524 \\
.70141 \\
.39428\end{array}$ & $\begin{array}{r}1.02272 \\
.97387 \\
.94570 \\
.99565 \\
1.03812 \\
1.01974 \\
1.02133 \\
.96246 \\
.94448 \\
.90992 \\
.83950 \\
.81024 \\
.72876 \\
.39912\end{array}$ \\
\hline & - Female & $\cdot$ & \\
\hline $\begin{array}{c}10-14 \\
15-19 \\
20-24 \\
25-29 \\
30-34 \\
35-39 \\
40-44 \\
45-49 \\
50-54 \\
55-59 \\
60-64 \\
65-69 \\
70-74 \\
75+\end{array}$ & $\begin{array}{r}1.01141 \\
.98072 \\
.96584 \\
.93177 \\
.92589 \\
.97239 \\
.97726 \\
.94291 \\
.93060 \\
.88371 \\
.85580 \\
.84380 \\
.72758 \\
.41696\end{array}$ & $\begin{array}{r}1.02529 \\
.98112 \\
.97279 \\
.97958 \\
.99320 \\
1.01301 \\
.98126 \\
.93287 \\
.93438 \\
.87480 \\
.84494 \\
.85601 \\
.77256 \\
.45244\end{array}$ & $\begin{array}{r}1.02277 \\
.98506 \\
.9968 \hat{\imath} \\
.99688 \\
1.03744 \\
1.02601 \\
1.00199 \\
.97607 \\
.94908 \\
.93487 \\
.88122 \\
.87438 \\
.82642 \\
.45644\end{array}$ \\
\hline
\end{tabular}


tion estimates to be impaired somewhat. Fortunately the concentration of migration in younger age classes has the effect of minimizing this potential shortcoming.

Experience with CSRs calculated for the U.S. leads us to several expectations about the pattern of CSRs in relation to Life Table Survival Ratios (LTRs) that permit a preliminary evaluation of the plausibility of the figures in Table 1. As a convenient reference Figure 1 shows the Native White Male CSRs for the U.S. for the decade 1950-60 (from Miller, 1964, Table M-4, p. 70) plotted on the same co-ordinates as the White Male LTRs for the same period, calculated from U.S. Life Tables. The configuration is pretty much representative of what would be seen for any recent decade, for males or females.

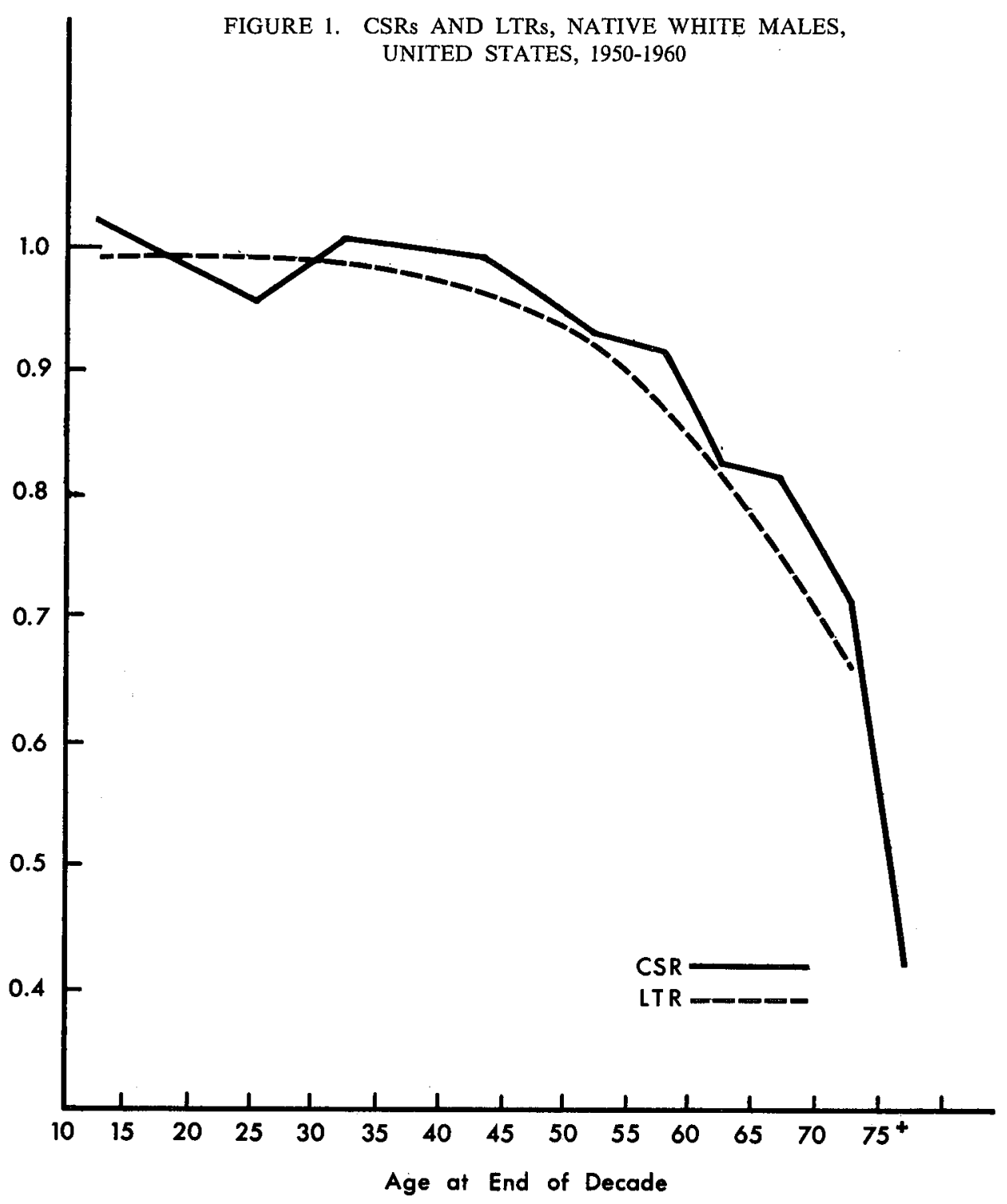


Some peculiarities for other periods will be noted below but limited space prohibits a graphic comparison for every decade.

The deviations of the CSRs from the LTRs in Figure 1 are indicative either of errors in census enumeration or flaws in the construction of the CSRs but are usually interpreted to represent primarily the former. Several such deviations appear systematically in virtually all CSR calculations. Most striking, perhaps, is the CSR in excess of unity for the age group $0 / 4-10 / 14$. Equally significant though, are CSRs for the young adult ages that fall well below the corresponding LTRs, and positive deviations of CSRs from LTRs in the ages (at end of decade) 30-34 through 40-44 and 65 and over. With the exception of the last, these are all interrelated. Substantial underenumeration of persons aged 20-24 would be expected to show up in an underestimate of survivorship for 10/14-20/24 and an overestimate for 20/24-30/34. Although the extent of deviation of CSRs from LTRs has varied, the pattern has been roughly the same for Native White Males for the three decades between 1930 and 1960. By and large, the same pattern is observed for females as well although the deviations of CSRs from LTRs tend to be smaller (with the exception of the positive deviation for ages 65 and over). Indeed, for the period 1950-60 the U.S. female CSRs appear to be consistently above the LTRs right through the early adult ages although one can still perceive the same pattern of peaks and troughs. For females, there is little less consistency in the appearance of peaks and troughs at specific ages.

If the pattern of enumeration error in the Canadian census is similar to that in the U.S., as has been assumed in this paper, we should observe a pattern of relationship of CSRs to LTRs for Canada similar to that for the U.S. Figure 2 presents Canadian data comparable to those for the U.S. shown in Figure 1. The principal feature of Figure 2 is that for males in Canada, 1951-61, the CSRs bear a relationship to LTRs that is remarkably similar to that seen for the U.S. For the $0 / 4-10 / 14$ age group the CSR is not only above the LTR but also in excess of unity. This is the case for males and females both for all three decades examined. For the age group 10/14-20/24 the CSR falls well below the LTR and for the later adult ages rather distinctly above. There is also a positive deviation for ages 65 and over. In short, there tends to be a one-to-one correspondence between the outstanding features of the Canadian and U.S. CSRs for the decade of the 1950s.

The similarity of Canadian with U.S. evidence holds reasonably well over time and between sexes as well. The succession of positive-negative-positive deviations over the age groups ending the decade $10 / 14,15 / 19$ or $20 / 24$ and then $30 / 34$ or $35 / 39$ occurs generally. For males in 1931-41, the trough occurs at the age group $25 / 29$, five years older than in the U.S. but, in consistent fashion, the succeeding peak occurs at an older age group as well. The Canadian pattern converges, in this respect, to that of the U.S. over the three decades. The deviations in Canada for females, as in the U.S., tend to be rather less than for males but the difference is not as marked.

Several differences between U.S. and Canadian relationships of CSRs to LTRs deserve notice. One is that the positive deviation of CSR from LTR for ages over 65 has been evolving from a very slight difference in 1931-41 to the quite substantial one in 1951-61 that approaches the magnitude of difference usually found in the U.S. Life tables are known to be less reliable at the older ages but the evidence from the Canadian CSRs lends weight to the view that the deviation owes more to the "passing" of foreign-born as natives at older ages. In 1931-41 foreign-born in Canada at older ages were proportionally few in number while Canadian-born in the U.S. had some tendency to "pass" as native-born there. Together these influences minimized the upward bias of the CSR. More recentlv a greater proportion of canadian-born at older ages continues to reside in Canada and there is an increasing number of foreign-born who may "pass" as Canadians. 


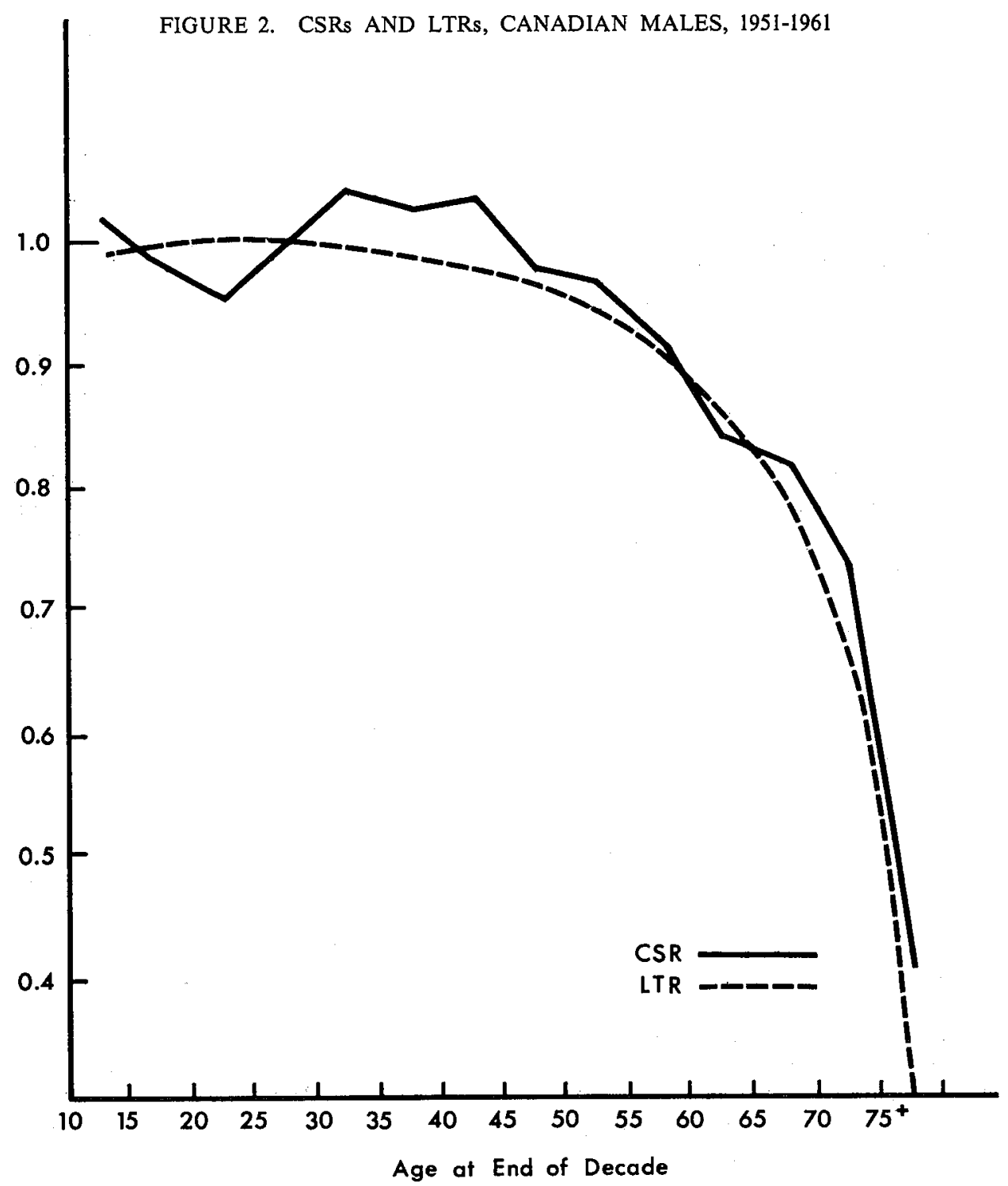

A second difference between the Canadian and U.S. CSRs is that the deviations of CSRs from LTRs in younger ages tend to be more pronounced in Canada. The implication is that young adult males have been underenumerated to a greater degree in the Canadian census. To a lesser extent, the same seems to hold for females as well.

While the CSRs that have been calculated for Canada seem plausible enough, their reliability cannot be precisely evaluated. Figures 3 and 4 present the male and female Canadian CSRs graphically for all three decades under consideration. Several observations stand out. One that has already been referred to is that the pattern of troughs and peaks in the early adult ages has shifted to younger age classes. A second observation worthy of note is that the whole curve of survivorship for 1941-51 appears to be low and that for 1951-61 
appears to be high. This is the case especially for males. The point is summarized in Table 2 where average CSRs for all ages are contrasted with average LTRs. These averages are computed by weighting each age-specific survival ratio by the number of persons in the age class at the beginning of the decade.

TABLE 2. COMPARISON OF AVERAGE CSR AND LTR VALUES FOR CANADA, INTERCENSAL DECADES 1931-41 TO 1951-61

CSR LTR

MALES

$\begin{array}{ccc}1931-41 & .90354 & .90878 \\ 1941-51 & .88807 & .90281 \\ 1951-61 & .91777 & .90348 \\ & & \text { FEMALES } \\ 1931-41 & .91251 & .91863 \\ 1941-51 & .92201 & .92027 \\ 1951-61 & .94052 & .92798\end{array}$

Source: Calculated from Table 1 using numbers of persons in each beginning-of-decade age group as weights.

If we keep in mind that the CSRs will take account of war deaths in the 1941-51 decade that would not show up in the LTRs, we might expect no improvement in survivorship over the preceding decade and possibly even some deterioration.

The greatest declines in the male survival ratio between 1931-41 and 1941-51 occur, however, at ages which are either too young or too old to be accounted for by war deaths. On the other hand, the indicated rise in survivorship is outstandingly large in the succeeding period. The implication seems to be that the 1951 Census of Canada was badly underenumerated relative to other years. There has been so little attention paid to the quality of enumeration of Canadian censuses that little can be found in the way of corroborative evidence. If the problems of enumerating young adults, and particularly single males, are more severe in large urban areas, the especially large shift of population to urban centres in the decade 1941-51 (Stone, 1967, p. 23) may have presented a situation to which census practice in Canada had not adequately adjusted.

The rather wide deviations of census from Life Table Survival Ratios for Canada are indicative of significant errors of census enumeration that will have to be coped with by any method of estimating population change due to migration as a residual. Whether failure to take into account errors of enumeration affected estimates of migration can be seen only by contrasting estimates made with LTRs with those made by the CSR method. By implication such a comparison will indicate whether the involved effort of producing CSR estimates for Canada can be justified.

\section{Census Survival Ratio Estimates of Population Change Due to Net Migration}

In the absence of any prior knowledge or independent determination of the magnitude of "true" net migration, there is no straightforward way in which one can choose between estimates of migration that have been produced by different methods. That being the case, it seems advisable to separate the discussion of the relative merits of the CSR and LTR methods of estimation, along with some attempt to reach a conclusion about the viability 


\section{R. Marvin McInnis}

of the CSR method with pooled Canadian-born cohorts of population, from a more straightforward comparison of the results obtained with the two methods. Conclusions are withheld therefore, until the last section of this paper. In this section the two alternative sets of estimates are merely presented and their salient features compared.

Paired CSR and LTR estimates of net population change due to migration are presented at the end of this paper in Appendix Tables I through VI. The mass of information represented in these tables is not easily summarized, yet even it involves a condensation of estimates for individual provinces into five regions. Many other details will have to be skipped over.

The CSR estimates presented here have involved the adjustment of the CSRs of Table 1 for apparent regional differences in survivorship through multiplication by ratios of regional to national LTRs. Except for a very few particular age classes the regional differences in survivorship are not significant. The adjustment is quite straightforwardly made; and is commonly used in these kinds of computations, and in the interests of producing CSR estimates of migration that are as free as possible of extraneous sources of error. The survival ratios used for the LTR estimates are from Stone (1967). Both the LTR and CSR estimates are by the forward survival ratio method and should involve the same structural error from an improper balancing of deaths to in- and out-migrants.

Migration totals, the rates for all ages, should be compared briefly. These are not expected to differ greatly, though; it is the age pattern of migration that is more at issue. For all ages, provincial net migration ratios by the two methods generally agree fairly closely. Since many of the net migration ratios are very low, percentage disagreements between the two series are not particularly meaningful. It is more instructive to express the differences relative to the base population which is the same in both cases. That indicates directly how much of an error one would make by choosing one set of figures over the other. The average disagreement would amount to only seven or eight per thousand-hardly a major number. One would not reach any important conclusions from the one series that would be negated by the other. This conclusion can be read two ways-for the aggregates of persons of all ages the effect of change in enumeration error is probably slight. On the other hand, the CSR estimates based wholly upon census data produce apparently reliable estimates. This suggests that a modified CSR approach might serve to produce the historical estimates of provincial net migration that are so sorely needed for Canada.

To the extent that the CSR and LTR estimates do in fact differ, it is in the way that might be expected from the inferred pattern of census enumeration error. In connection with the discussion of the construction of CSRs it was pointed out that the census of 1951 probably was underenumerated to a greater degree than either 1941 or 1961. That appears to be borne out. Such a pattern of enumeration error would lead, via the LTR method; to an algebraically downward bias of 1941-51 net migration and an upward bias for 1951-61. For males this pattern quite clearly appears. All CSR estimates for 1941-51 are above the LTR estimates, even if the differences are not pronounced. For that decade, the LTR method would have assigned Quebec a slightly negative net migration ratio. By the CSR method, Quebec's net migration, 1941-51, is very slightly positive. So much significance should not be assigned to the zero balance mark. Proportionately, the largest difference is found in Ontario where the LTR estimate of 56 per thousand falls well short of the CSR figure of 68 per thousand. In the following decade the CSR estimates tend to be below the LTR estimates. By the CSR method, the Atlantic region in 1951-61 would have lost males by net migration to the extent of 33 per thousand end-of-decade population. The differences are much milder for females. Nevertheless, they tend to be in the same direction.

The choice between CSR and LTR estimates of migration ratios lies especially in the 
contrasting age patterns they reveal. Many studies have shown that migration tends to follow a fairly regular pattern by age-rising from low to medium values for the youngest age groups to peak values in the young adult ages and then falling off in later middle and old age. Both series tend to show approximately that standard pattern, but with notable differences from age to age. For each decade there are 70 male and 70 female pairs of CSR and LTR migration ratios, or 420 pairs in all. The overall average difference between these pairs, expressed in relation to the LTR estimate, is 133 per cent. This figure might look startlingly high but this results from the many low base values of the LTR estimates so that in many cases the differences between the two estimates are several times greater than the LTR estimate itself. Almost half the time the difference is in excess of 50 per cent of the LTR estimate and is less than 25 per cent in only one-third of all cases.

The two sets of estimates give much less appearance of being in disagreement if we express the differences between them in relation to the base (end-of-decade) population. On the average, over all of the possible comparisons, the difference is 27.5 per thousand base population. However, the difference again varies widely. Understandably, it tends to be the greatest at ages such as 10-14, 25-29 and 30-34 where the apparent degree of enumeration error in the census population totals is the greatest. The estimates also tend to differ considerably at older ages. The LTR method frequently shows a strong upward bias in migration ratios estimated for persons above age 65 at the end of the intercensal period.

Limitations of space do not permit the examination of age curves of migration for all periods and regions. Two fairly representative examples are given in Figure 3 . The top panel shows migration ratios by five-year age groups for Ontario males in 1931-1941. CSR estimates are represented by dark and LTR by light coloration. Rather typically of a situation where migration is at a relatively low rate, the two sets of estimates differ considerably. For the youngest age group the LTR estimate is double the CSR estimate, reflecting the common recapturing of migrants by the LTR method of the nonenumerated members of the $0-4$ cohort. The CSR pattern is more regular, rising to rates of population gain through migration that are well above the LTR estimates in the younger adult ages. The LTR estimate for 25-29 year olds drops to four per thousand from 31 for the preceding age group, while the CSR estimate shows a smoother gradation, the $25-29$ year old figure being 50 per thousand-far above the corresponding LTR estimate, but only modestly below the CSR ratio of 65 for the next younger group. The downward bias of the LTR method pushes the migration ratios well below zero for the ages 55-59 and 60-64. The CSR estimate rests very close to zero over that age range, dropping to -5 only for the 55-59 year group.

Net migration ratios for males in the Atlantic region in the period 1951-1961 are displayed in the lower panel of Figure 3. Here we have a situation of generally heavy net out= migration. We would expect the two methods to show a closer correspondence under these circumstances. It should be noted that even closer agreement can be found in estimates for the Prairie region and B.C. in the 1941-1951 decade. For the Atlantic region males in 195161 there are still some visible differences between the two sets of migration ratios by fiveyear age groups. The LTR method has net out-migration more heavily concentrated in the younger ages-20-24 and 25-29. By the CSR method we get a less pronounced peak and substantial levels of out-migration in the age span 30 to 44 where the LTR method indicates very little. The differences are sufficient possibly to affect the outcome of some kinds of analytical questions.

A choice between the two methods hinges on one's expectations about continuity in the age pattern of net migration. One can conceive of situations where there might be sharp breaks in the age pattern but generally we would expect the kind of continuity that seems to be better reproduced by the CSR method. We are inclined to rest on the Marshallian dictum that natura non facit saltum. 
FIGURE 3.
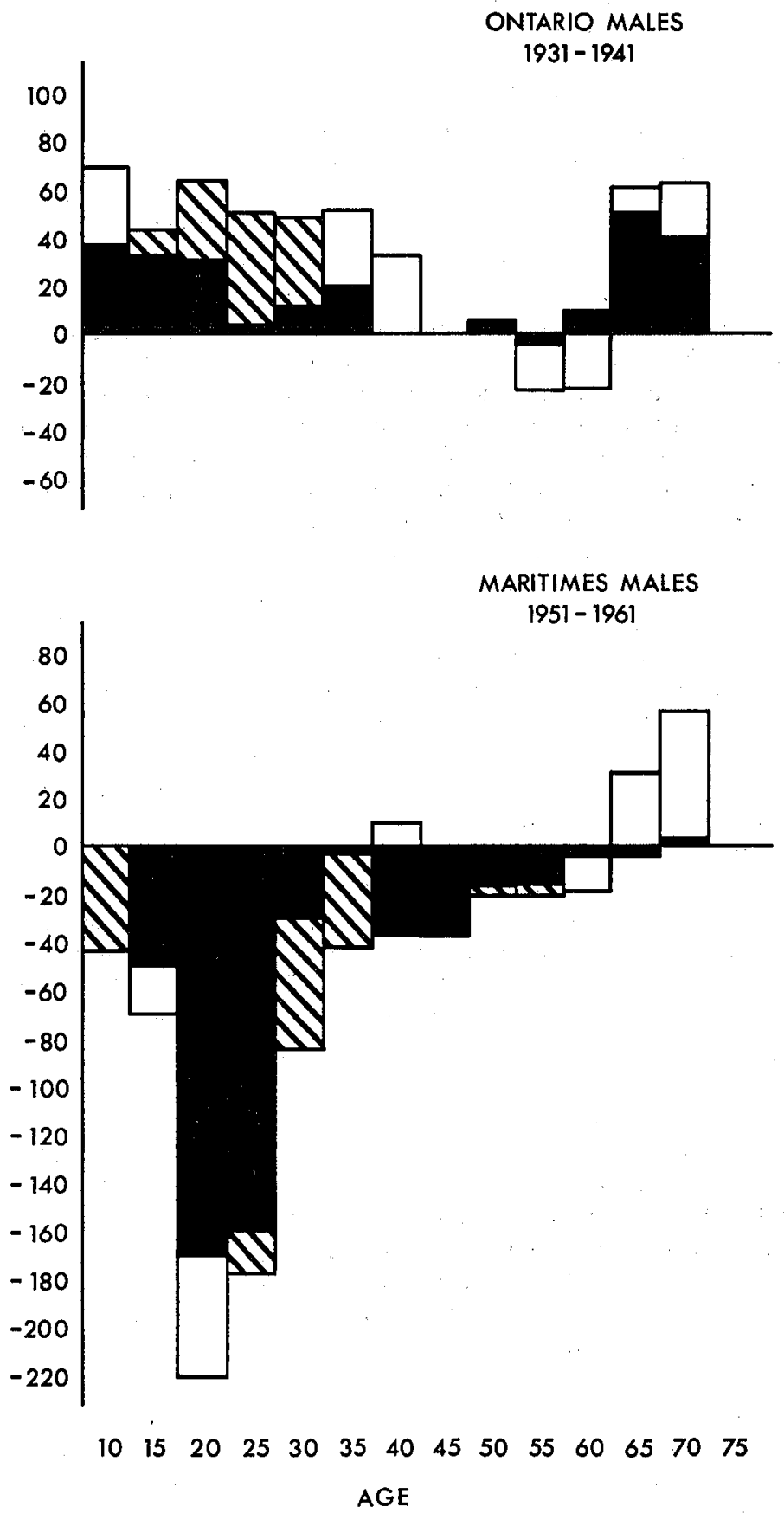

DV $C S R>L T R$

$\square L T R>C S R$ 
There may be relatively few analytical purposes for which five-year detail is required. For many studies, analysts wish to focus on a central group of highly mobile and possibly more homogeneously motivated persons. For example, an interest in migration as part of the process by which labour resources get allocated among regions may be satisfied by estimates of the migration of young adult males. One can see from the diagrams presenting the differences between Census and Life Table Survival Ratios that the differences are quite marked within the age classes that might be designated "young adult males." Unfortunately, there does not appear to be enough consistency over time to conclude that one particular age grouping would minimize the difference between results from the alternative methods of estimation. For any reasonable age grouping the differences are greatest in the decade 193141 but are minimized, at 48 per cent, for the group 20-44. In the most recent decade a minimum average difference of 13 per cent is found for the slightly narrower age group 2029. That age group has an average difference of 36 per cent in the decade 1941-51-about the same in that year as for slightly narrower or broader groupings. Even with the cancellation afforded by combining age classes with differences in opposite directions, the two methods of estimation still produce results that differ by a rather substantial amount.

The differences between CSR and LTR migration rates for any specific age class tend, by virtue of their construction, to be about the same fraction of the base population in that age class across regions. This implies what is seen in both the summary charts and the Appendix Tables, that the choice of method makes a greater difference to migration estimates where the net balance of population change due to migration is relatively small. Large migration flows show through clearly enough whatever the method. There is nothing new in this; we were warned that this was the nature of likely errors in residual estimates of net migration years ago by Hamilton and Henderson (1944). The calculations made here confirm that the errors indeed appear as they have long been expected. That is, the deviations between CSR and LTR migration rates are the sort predicted by the underlying theory.

An extended comparison of the CSR migration estimates made here with the Place of Birth Survival Ratio estimates by George (1970) is not undertaken here. The use of any form of reasonable survival ratios with place of birth data is valuable as a means of getting at gross flows of migration. That is a problem which no procedure for estimating net migration even addresses. What may be at issue is whether there is any possible gain from making Census Survival Ratios specific to provinces of birth. If data were fully available it would be a relatively straightforward extension of the CSR procedure. The key problem again lies with the open nature of the Canadian population. We know of the Canadianborn residing in the United States only whether they are ethnically French or English. To construct Place of Birth Survival Ratios, George (1970) had to allocate this sometimes large component of the Canadian-born among provinces of birth in proportion to Canadian-born of French origin residing in Canada. I have tried to indicate that using the pooled Canadian-born of the Canadian and U.S. censuses to generate Census Survival Ratios for application in Canada strains both the data and the estimating procedure to the utmost. Yet it produces a set of migration estimates that give every appearance of being an improvement over what can be obtained using Life Table Survival Ratio. Whether to manipulate the data in a substantial way even further as George does in principle offers little advantage, if one's interest is to obtain an estimate of net migration, but at a cost of even further and more courageous assumption.

What has been demonstrated in this paper is that enumeration errors of a well-known sort afflict Canadian census totals of population to such an extent that to ignore them in making estimates of the net change in population due to migration can be perilous. Even a partial and imperfect attempt at constructing Census Survival Ratios can go a long way in 
cleaning up provincial net migration estimates, making them more plausible and strengthening our convictions that they are showing us approximately the true story.

\section{APPENDIX TABLE I}

POPULATION CHANGE DUE TO NET MIGRATION, PER 1000 END OF DECADE POPULATION-ESTIMATES BY CSR AND LTR METHODS, CANADIAN REGIONS,

$$
\text { 1931-1941 }
$$

\section{MALES}

\begin{tabular}{|c|c|c|c|c|c|}
\hline $\begin{array}{l}\text { Age at end of } \\
\text { decade }\end{array}$ & Maritimes & $\begin{array}{r}\text { Quebec } \\
\text { (CSF }\end{array}$ & Ontario & Prairies & B.C. \\
\hline $\begin{array}{c}10-14 \\
15-19 \\
20-24 \\
25-29 \\
30-34 \\
35-39 \\
40-44 \\
45-49 \\
50-54 \\
55-59 \\
60-64 \\
65-69 \\
70-74 \\
75+\end{array}$ & $\begin{array}{r}13 \\
-2 \\
11 \\
-18 \\
\star \\
19 \\
-6 \\
-2 \\
4 \\
-29 \\
-3 \\
59 \\
12 \\
-36\end{array}$ & $\begin{array}{r}21 \\
16 \\
-5 \\
23 \\
7 \\
-23 \\
-56 \\
* \\
-3 \\
-5 \\
13 \\
34 \\
17 \\
33\end{array}$ & $\begin{array}{r}35 \\
44 \\
65 \\
50 \\
48 \\
20 \\
\star \\
* \\
6 \\
-5 \\
16 \\
51 \\
41 \\
73\end{array}$ & $\begin{array}{l}-61 \\
-56 \\
-96 \\
-154 \\
-180 \\
-206 \\
-185 \\
-120 \\
-102 \\
-94 \\
-63 \\
-43 \\
-57 \\
46\end{array}$ & $\begin{array}{r}132 \\
132 \\
167 \\
180 \\
167 \\
66 \\
38 \\
20 \\
6 \\
6 \\
61 \\
80 \\
39 \\
177\end{array}$ \\
\hline All ages & 2 & $\begin{array}{l}3 \\
\text { (LTF }\end{array}$ & 27 & -90 & 81 \\
\hline $\begin{array}{c}10-14 \\
15-19 \\
20-24 \\
25-29 \\
30-34 \\
35-39 \\
40-44 \\
45-49 \\
50-54 \\
55-59 \\
60-64 \\
65-69 \\
70-74 \\
75+\end{array}$ & $\begin{array}{r}50 \\
-9 \\
-25 \\
-68 \\
-38 \\
51 \\
28 \\
-\quad 1 \\
4 \\
-49 \\
-44 \\
69 \\
35 \\
5\end{array}$ & $\begin{array}{r}58 \\
6 \\
-41 \\
-25 \\
-31 \\
9 \\
-21 \\
\star \\
-4 \\
-25 \\
-26 \\
45 \\
40 \\
71\end{array}$ & $\begin{array}{r}71 \\
34 \\
31 \\
4 \\
12 \\
52 \\
34 \\
\star \\
5 \\
-25 \\
-24 \\
62 \\
63 \\
109\end{array}$ & $\begin{array}{l}-20 \\
-67 \\
-135 \\
-211 \\
-224 \\
-168 \\
-145 \\
-120 \\
-103 \\
-115 \\
-106 \\
-32 \\
-33 \\
83\end{array}$ & $\begin{array}{r}164 \\
123 \\
137 \\
139 \\
135 \\
96 \\
71 \\
19 \\
5 \\
-\quad 14 \\
23 \\
91 \\
61 \\
210\end{array}$ \\
\hline A11 ages & -3 & * & 23 & -96 & 77 \\
\hline
\end{tabular}

* Less than $1 / 2$ of $1 / 1000$.

Sources: CSRs from Table 1, LTRs from Stone [1967] Appendix L Population data - Canada, D.B.S., 1962, Table 20. 
APPENDIX TABLE II

POPULATION CHANGE DUE TO NET MIGRATION, PER 1000 END OF DECADE POPULATION-ESTIMATES BY CSR AND LTR METHODS, CANADIAN REGIONS, $1931-1941$

\section{FEMALES}

Age at end of Maritimes Quebec Ontario Prairies B.C. decade

$$
\text { (CSR). }
$$

$\begin{array}{rrrrrr}10-14 & 16 & 20 & 37 & -60 & 132 \\ 15-19 & -5 & 20 & 32 & -62 & 135 \\ 20-24 & -45 & 29 & 53 & -140 & 184 \\ 25-29 & -55 & 12 & 64 & -177 & 209 \\ 30-34 & -26 & -8 & 50 & -149 & 160 \\ 35-39 & 4 & -16 & 25 & -105 & 114 \\ 40-44 & \star & -15 & 6 & -107 & 96 \\ 45-49 & -14 & -8 & -12 & -117 & 62 \\ 50-54 & 7 & 2 & 8 & -92 & 90 \\ 55-59 & -17 & 1 & 11 & -87 & 83 \\ 60-64 & -22 & 5 & 10 & -97 & 102 \\ 65-69 & 10 & 17 & 38 & -49 & 139 \\ 70-74 & 63 & 49 & 65 & -18 & 144 \\ 75+ & -16 & 56 & 83 & 54 & 186 \\ \text { A11 ages } & -9 & 8 & 28 & -82 & 114\end{array}$

(LTR)

\begin{tabular}{|c|c|c|c|c|c|}
\hline $\begin{array}{c}10-14 \\
15-19 \\
20-24 \\
25-29 \\
30-34 \\
35-39 \\
40-44 \\
45-49 \\
50-54 \\
55-59 \\
60-64 \\
65-69 \\
70-74 \\
75+\end{array}$ & $\begin{array}{r}48 \\
-11 \\
-62 \\
-103 \\
-75 \\
11 \\
19 \\
-23 \\
\star \\
-45 \\
-45 \\
42 \\
63 \\
52\end{array}$ & $\begin{array}{r}53 \\
15 \\
13 \\
-33 \\
-56 \\
-9 \\
3 \\
-17 \\
-5 \\
-32 \\
-18 \\
49 \\
49 \\
119\end{array}$ & $\begin{array}{r}69 \\
27 \\
38 \\
21 \\
6 \\
32 \\
24 \\
-22 \\
\star \\
-22 \\
-12 \\
70 \\
64 \\
145\end{array}$ & $\begin{array}{l}-25 \\
-67 \\
-158 \\
-231 \\
-204 \\
-98 \\
-88 \\
-127 \\
-100 \\
-123 \\
-121 \\
-15 \\
-19 \\
118\end{array}$ & $\begin{array}{r}160 \\
130 \\
171 \\
173 \\
121 \\
120 \\
112 \\
54 \\
84 \\
53 \\
82 \\
167 \\
143 \\
240\end{array}$ \\
\hline 111 ages & -73 & 2 & 23 & -90 & 109 \\
\hline
\end{tabular}

* Less than $1 / 2$ of $1 / 1000$.

Sources: CSRs from Table 1, LTRs from Stone [1967] Appendix L Population data - Canada, D.B.S., 1962, Table 20. 
R. Marvin McInnis

APPENDIX TABLE III

POPULATION CHANGE DUE TO NET MIGRATION, PER 1000 END OF DECADE POPULATION-ESTIMATES BY CSR AND LTR METHODS, CANADIAN REGIONS, 1941-1951

MALES

\begin{tabular}{|c|c|c|c|c|}
\hline $\begin{array}{l}\text { Age at end of } \\
\text { decade }\end{array}$ & Maritimes** & $\begin{array}{l}\text { Quebec } \\
\qquad(\mathrm{CSR})\end{array}$ & Ontario & Prairies \\
\hline $\begin{array}{c}10-14 \\
15-19 \\
20-24 \\
25-29 \\
30-34 \\
35-39 \\
40-44 \\
45-49 \\
50-54 \\
55-59 \\
60-64 \\
65-69 \\
70-74 \\
75+\end{array}$ & $\begin{array}{r}-28 \\
-78 \\
-205 \\
-205 \\
-182 \\
-121 \\
-66 \\
-41 \\
4 \\
-\quad 2 \\
17 \\
46 \\
43 \\
-12\end{array}$ & $\begin{array}{r}3 \\
-4 \\
-19 \\
-6 \\
23 \\
-6 \\
2 \\
10 \\
36 \\
10 \\
27 \\
27 \\
20 \\
30\end{array}$ & $\begin{array}{r}57 \\
80 \\
140 \\
163 \\
103 \\
8 \\
71 \\
66 \\
69 \\
49 \\
41 \\
62 \\
56 \\
28\end{array}$ & $\begin{array}{l}-81 \\
-95 \\
-143 \\
-166 \\
-166 \\
-114 \\
-83 \\
-62 \\
-64 \\
-89 \\
-101 \\
-119 \\
-129 \\
-23\end{array}$ \\
\hline A11 ages & -61 & $\begin{array}{l}4 \\
\text { (LTR) }\end{array}$ & 68 & -85 \\
\hline $\begin{array}{c}10-14 \\
15-19 \\
20-24 \\
25-29 \\
30-34 \\
35-39 \\
40-44 \\
45-49 \\
50-54 \\
55-59 \\
60-64 \\
65-69 \\
70-74 \\
75+\end{array}$ & $\begin{array}{r}16 \\
-106 \\
-285 \\
-279 \\
-219 \\
-101 \\
-48 \\
-71 \\
-13 \\
-64 \\
-35 \\
-34 \\
65 \\
55\end{array}$ & $\begin{array}{r}45 \\
-31 \\
-87 \\
-67 \\
-7 \\
11 \\
19 \\
-19 \\
20 \\
-52 \\
-25 \\
35 \\
43 \\
94\end{array}$ & $\begin{array}{r}98 \\
56 \\
83 \\
111 \\
76 \\
93 \\
87 \\
39 \\
53 \\
-10 \\
-9 \\
70 \\
78 \\
92\end{array}$ & $\begin{array}{l}-35 \\
-124 \\
-219 \\
-238 \\
-202 \\
-94 \\
-64 \\
-92 \\
-82 \\
-156 \\
-159 \\
-109 \\
-102 \\
44\end{array}$ \\
\hline All ages & -74 & -9 & 56 & -100 \\
\hline
\end{tabular}

** Excludes Newfoundl and

Sources: CSRs from Table T; LTRs from Stone [1967] Appendix L Population data - Canada, D.B.S., 1962, Table 20. 
APPENDIX TABLE' IV

POPULATION CHANGE DUE TO NET MIGRATION, PER 1000 END OF DECADE POPULATION-ESTIMATES BY CSR AND LTR METHODS, CANADIAN REGIONS, 1941-1951

\section{FEMALES}

\begin{tabular}{|c|c|c|c|c|c|}
\hline $\begin{array}{c}\text { Age at end of } \\
\text { decade }\end{array}$ & Maritimes** & $\begin{array}{r}\text { Quebec } \\
\text { (CS }\end{array}$ & Ontario & Prairies & B.C. \\
\hline $\begin{array}{c}10-14 \\
15-19 \\
20-24 \\
25-29 \\
30-34 \\
35-39 \\
40-44 \\
45-49 \\
50-54 \\
55-59 \\
60-64 \\
65-69 \\
70-74 \\
75+\end{array}$ & $\begin{array}{l}-27 \\
-64 \\
-179 \\
-183 \\
-142 \\
-96 \\
-36 \\
-25 \\
-\quad 6 \\
-\quad 2 \\
-\quad 6 \\
-\quad 34 \\
-59\end{array}$ & $\begin{array}{r}-4 \\
3 \\
12 \\
4 \\
-7 \\
-31 \\
3 \\
12 \\
51 \\
9 \\
21 \\
12 \\
25 \\
-8\end{array}$ & $\begin{array}{r}56 \\
60 \\
109 \\
166 \\
97 \\
57 \\
59 \\
66 \\
57 \\
52 \\
35 \\
35 \\
59 \\
13\end{array}$ & $\begin{array}{l}-80 \\
-110 \\
-165 \\
-178 \\
-161 \\
-126 \\
-83 \\
-72 \\
-87 \\
-91 \\
-120 \\
-136 \\
-83 \\
-60\end{array}$ & $\begin{array}{l}223 \\
239 \\
275 \\
327 \\
271 \\
206 \\
217 \\
219 \\
210 \\
203 \\
206 \\
198 \\
179 \\
148\end{array}$ \\
\hline All ages & -56 & $\begin{array}{c}3 \\
(L T)\end{array}$ & 60 & -93 & 188 \\
\hline $\begin{array}{c}10-14 \\
15-19 \\
20-24 \\
25-29 \\
30-34 \\
35-39 \\
40-44 \\
45-49 \\
50-54 \\
55-59 \\
60-64 \\
65-69 \\
70-74 \\
75+\end{array}$ & $\begin{array}{r}12 \\
-75 \\
-199 \\
-190 \\
-130 \\
-59 \\
-27 \\
-59 \\
-22 \\
-57 \\
-67 \\
17 \\
59 \\
50\end{array}$ & $\begin{array}{r}34 \\
-8 \\
-\quad 4 \\
-2 \\
4 \\
4 \\
12 \\
-20 \\
1 \\
-39 \\
-32 \\
34 \\
50 \\
95\end{array}$ & $\begin{array}{r}91 \\
51 \\
94 \\
161 \\
107 \\
89 \\
67 \\
36 \\
42 \\
-\quad 4 \\
-18 \\
57 \\
83 \\
114\end{array}$ & $\begin{array}{l}-39 \\
-122 \\
-185 \\
-188 \\
-149 \\
-88 \\
-74 \\
-107 \\
-104 \\
-156 \\
-182 \\
-110 \\
-56 \\
48\end{array}$ & $\begin{array}{l}250 \\
225 \\
263 \\
323 \\
279 \\
233 \\
223 \\
194 \\
198 \\
156 \\
162 \\
215 \\
200 \\
235\end{array}$ \\
\hline All ages & -53 & 3 & 61 & -96 & 189 \\
\hline
\end{tabular}

** Excludes Newfoundl and

Sources: CSRs from Table 1, LTRs from Stone [1967] Appendix L. Population data - Canada, D.B.S., 1962, Table 20. 
R. Marvin McInnis

APPENDIX TABLE $V$

POPULATION CHANGE DUE TO NET MIGRATION, PER 1000 END OF DECADE POPULATION-ESTIMATES BY CSR AND LTR METHODS, CANADIAN REGIONS, 1951-1961

MALES

\begin{tabular}{ccccrr}
$\begin{array}{c}\text { Age at end of } \\
\text { decade }\end{array}$ & Atlantict & Quebec & Ontario & Prairies & B.C. \\
& \multicolumn{7}{c}{ (CSR) } \\
$10-14$ & -44 & 27 & 112 & 8 & 146 \\
$15-19$ & -51 & 25 & 106 & 6 & 139 \\
$20-24$ & -169 & 41 & 176 & 16 & 212 \\
$25-29$ & -175 & 76 & 252 & 69 & 332 \\
$30-34$ & -86 & 78 & -213 & 82 & 296 \\
$35-39$ & -42 & 72 & 165 & 55 & 221 \\
$40-44$ & -35 & 39 & 111 & 16 & 165 \\
$45-49$ & -37 & 45 & 96 & 17 & 145 \\
$50-54$ & -21 & 43 & 75 & 9 & 118 \\
$55-59$ & -21 & 20 & 43 & -9 & 89 \\
$60-64$ & -6 & 27 & 27 & -55 & 106 \\
$65-69$ & -7 & 14 & 22 & -45 & 115 \\
$70-74$ & -3 & 5 & 33 & 25 & 155 \\
$75+$ & 20 & 56 & 64 & 16 & 138 \\
& & & & & 75 \\
A11 ages & -44 & 33 & 97 & &
\end{tabular}

(LTR)

\begin{tabular}{|c|c|c|c|c|c|}
\hline $\begin{array}{c}10-14 \\
15-19 \\
20-24 \\
25-29 \\
30-34 \\
35-39 \\
40-44 \\
45-49 \\
50-54 \\
55-59 \\
60-64 \\
65-69 \\
70-74 \\
75+\end{array}$ & $\begin{array}{r}-1 \\
-71 \\
-221 \\
-161 \\
-29 \\
-\quad 3 \\
11 \\
-37 \\
-15 \\
-13 \\
-19 \\
31 \\
55 \\
63\end{array}$ & $\begin{array}{r}58 \\
7 \\
-\quad 1 \\
87 \\
127 \\
107 \\
83 \\
45 \\
48 \\
27 \\
15 \\
50 \\
56 \\
113\end{array}$ & $\begin{array}{r}140 \\
90 \\
140 \\
261 \\
255 \\
197 \\
151 \\
95 \\
80 \\
50 \\
15 \\
59 \\
83 \\
105\end{array}$ & $\begin{array}{r}39 \\
-13 \\
-28 \\
80 \\
131 \\
91 \\
60 \\
17 \\
14 \\
-\quad 1 \\
-\quad 20 \\
-16 \\
9 \\
130\end{array}$ & $\begin{array}{r}173 \\
123 \\
177 \\
340 \\
334 \\
251 \\
203 \\
145 \\
123 \\
96 \\
73 \\
140 \\
162 \\
192\end{array}$ \\
\hline ages & -33 & 44 & 108 & 30 & 149 \\
\hline
\end{tabular}

+ Includes Newfoundland

Sources: CSRs from Table 1, LTRs from Stone [1967] Appendix L. Population data - Canada, D.B.S., 1962, Table 20. 
APPENDIX TABLE VI

POPULATION CHANGE DUE TO NET MIGRATION, PER 1000 END OF DECADE POPULATION-ESTIMATES BY CSR AND LTR METHODS, CANADIAN REGIONS, 1951-1961

\section{FEMALES}

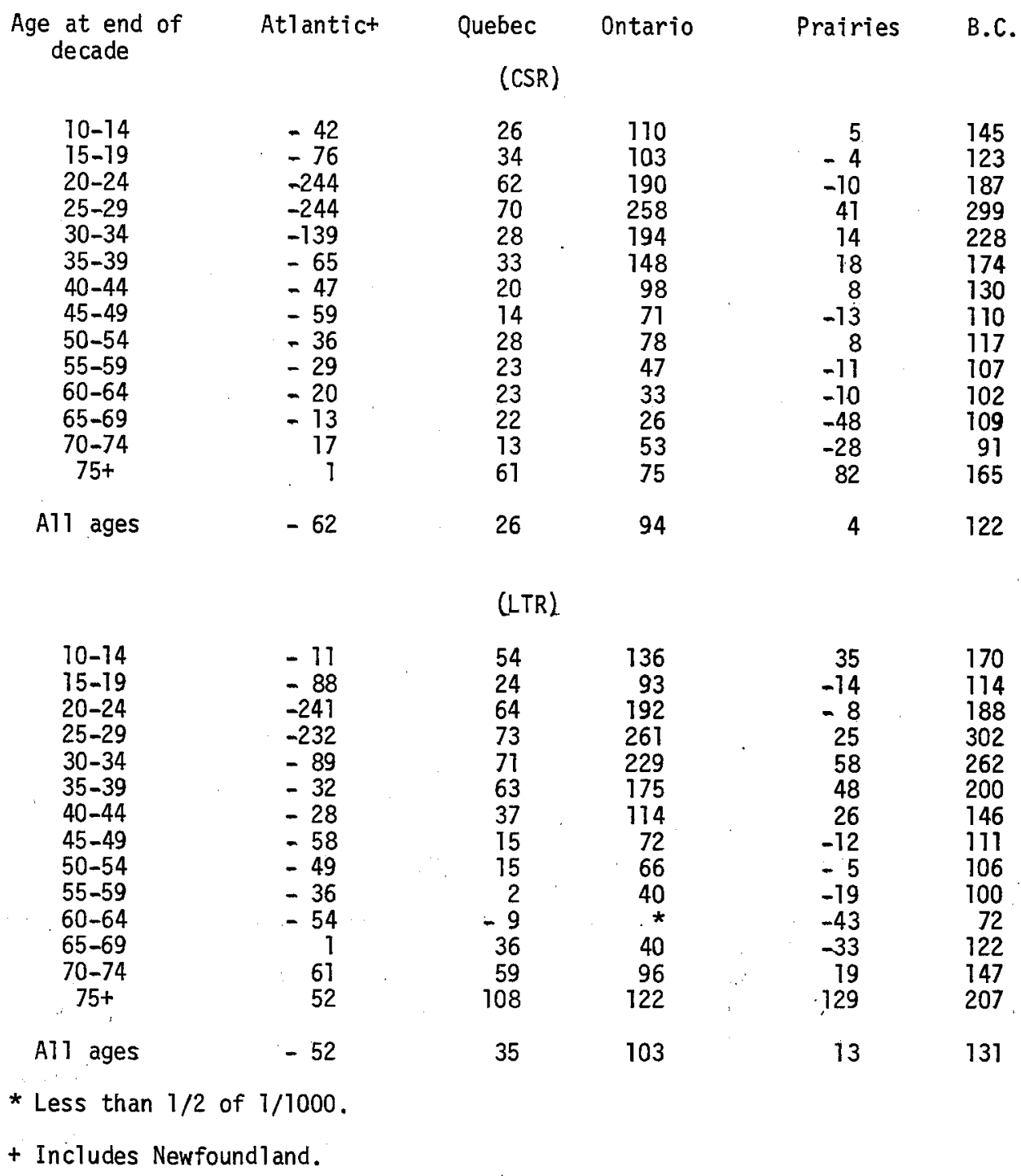

Sources: CSRs from Table 1, LTRs from Stone [1967] Appendix L. Population data - Canada, D.B.S., 1962, Table 20. 


\section{R. Marvin Mclnnis}

\section{Acknowledgments}

The research underlying this paper was supported by the Canada Council. Valuable assistance in developing the CSR estimates was provided by Charles Pye.

A revision of a paper prepared in 1969 , widely circulated in mimeo and intended to be a chapter in a book, yet incomplete.

\section{References}

Anderson, Isabel B. 1966. Internal Migration in Canada, 1921-1961. Ottawa: Economic Council of Canada, Staff Study 13.

Buckley, Kenneth A. H. 1962. Historical Estimates of Internal Migration. Canadian Political Science Association, Conference on Statistics, 1960, Papers. Toronto: University of Toronto Press.

Canada, Bureau of Statistics. 1962. Census of Canada, 1961. Bulletin 1.2-2. Ottawa: The Queen's Printer.

George, M. V. 1970. Internal Migration in Canada: Demographic Analyses. Dominion Bureau of Statistics, 1961 Census Monograph. Ottawa: The Queen's Printer.

Hamilton, C. Horace. 1966. Effect of Census Errors on the Measurement of Net Migration. Demography 3:393-415.

Hamilton, C. Horace and F. M. Henderson. 1944. Use of the Survival Rate Method in Measuring Net Migration. Journal of the American Statistical Association 39:197-206.

Keyfitz, Nathan. 1950. The Growth of Canadian Population, Population Studies 4:47-63.

Lee, Everett S., et al. 1957. Population Redistribution and Economic Growth: Volume I. Methodological Considerations and Reference Tables. Philadelphia: American Philosophical Society.

Miller, Ann Ratner. 1964. Net Intercensal Migration to Large Urban Areas of the United States. Analytical and Technical Report No. 4. Philadelphia: University of Pennsylvania Population Studies Center.

McDougall, Duncan M. 1961. Immigration into Canada, 1851-1920. Canadian Journal of Economics and Political Science 27:162-175.

Price, Daniel O. 1955. Examination of Two Sources of Error in the Estimation of Net Internal Migration. Journal of the American Statistical Association 50:689-700.

Stone, Leroy O. 1967. Urban Development in Canada. Dominion Bureau of Statistics, 1961 Census Monograph. Ottawa: The Queen's Printer.

1969. Migration in Canada: Regional Aspects. Dominion Bureau of Statistics, 1961 Census Monograph. Ottawa: The Queen's Printer.

Tarver, James D. 1962. Evaluation of Census Survival Rates in Estimating Intercensal State Net Migration. Journal of the American Statistical Association 57:841-862.

Truesdell, Leon E. 1943. The Canadian-born in the United States. New Haven: Yale University Press.

U.S. Bureau of the Census. 1943. Census of Population 1940, Special Report on Nativity and Parentage of the White Population. Washington: Government Printing Office.

1954. Census of Population 1950. Special Reports. Nativity and Parentage. P-E No. 3A. Washington: Government Printing Office.

1965. Census of Population 1960. Subject Reports Nativity and Parentage, Final Report. PC(2)-1A. Washington: Government Printing Office.

Urquhart, M. C. and K. A. H. Buckley (eds.). 1965. Historical Statistics of Canada. Section A, Population and Migration. Cambridge: Cambridge University Press.

Zachariah, K. C. 1962. A Note on the Census Survival Ratio Method of Estimating Net Migration. Journal of the American Statistical Association 57:175-183.

Received November, 1974. 